\title{
O circuito artístico e os discursos críticos: Renina Katz, os salões e a imprensa
}

\author{
João Paulo Ovidio ${ }^{7}$ \\ DOI 10.20396/eha.vi14.3392
}

A década de 1940 no Rio de Janeiro suscita um período fértil para a consolidação da arte moderna no país. É nesse momento em que ocorre a separação das tendências artísticas no salão em Divisão Geral e Divisão Moderna, conquista alcançada por meio da Portaria ministerial nº 140 , de 25 de julho de 1940. A cisão reforça a diferença estética entre os dois, o que permite uma melhor avaliação dos trabalhos, agrupados por afinidades plásticas, posto que os critérios para os primeiros não cabem aos últimos e vice-versa. Uma série de embates entre artistas conservadores e progressistas se fizeram presente nos salões, tanto por meio dos trabalhos expostos, como devido a legislação responsável pelo funcionamento do certame. De um lado, os defensores da manutenção da tradição acadêmica, do outro, os interessados nas novas tendências. A polaridade estava imbricada a uma ideologia plástica, responsável por alimentar o discurso de rivalidade, onde um era constantemente "demonizado" pelo outro.

No Art 7. $\S 4^{\circ}$ consta a área destinada para cada seção, sendo previsto três metros quadrados para desenho e artes gráficas - seção de nosso interesse - e dois metros quadrados para gravura, reservada a glíptica, enquanto as outras técnicas ocupavam até dez metros quadrados. Na época em questão os trabalhos em papéis recebiam menor reconhecimento, uma desvalorização do suporte. No que se refere especificamente a gravura artística, a produção ainda era incipiente, tanto como havia a depreciação do múltiplo, natureza desse meio expressivo. A insistência de mestres como Carlos Oswald no Liceu de Artes e Ofícios (LAO) e a presença de AxI Leskoschek no Rio de Janeiro contribuíram para uma mudança significativa no circuito artístico. Tais mestres foram responsáveis pela formação de uma nova geração, descrita pelo crítico de arte José Roberto Teixeira Leite como a fase de afirmação (1945-1955).

O salão era um espaço de privilégio, uma vez que nem todos os inscritos eram aceitos, sendo necessário submeter os trabalhos a uma comissão que decidia quem podia ou não expor. Além disso, era um espaço de prestígio, os artistas conquistavam reconhecimento e os trabalhos visibili-

1 Mestrando pelo programa de Pós-Graduação em Artes Visuais da Universidade Federal do Rio de Janeiro, na linha de pesquisa História e Crítica da Arte. - Bolsista do Conselho Nacional de Pesquisa e Desenvolvimento Científico e Tecnológico (CNPq). 
dade. Portanto, estimulava a disputa entre a classe artística, que compreendia a participação como uma oportunidade de projeção, bem como de legitimação da carreira. Anualmente era apresentado o panorama, onde era possível ter acesso a produção recente dos artistas, assim como conhecer novos nomes, sendo uma plataforma de inserção ao circuito.

Os membros do júri avaliavam e conferiam prêmios aos trabalhos que consideravam serem os melhores, no entanto, as conquistas estavam condicionadas a uma progressão, sendo imposta uma ordem para alcançar o prêmio mais cobiçado: Viagem ao Estrangeiro². Tal condicionante estimulavam os artistas a trilhar uma carreira nos salões. Os críticos acompanhavam os avanços e decadência do certame, produziam discursos a fim de questionar determinadas escolhas e reconhecer outras. O público ficava a par da repercussão e polêmicas através da imprensa, principal veículo de informação da época. Os conflitos proporcionaram debates efervescentes, deram fôlego para a tendência moderna, que conquistou espaço aos poucos, fruto de árduo confronto de ideias e ideais.

Em 1946, os vinculados à tradição acadêmica se articularam a fim de boicotar a participação dos modernos. Não concordavam com a mesma distribuição dos prêmios, compreendiam o benefício do prêmio de Viagem ao Estrangeiro, para ambas as divisões, como um modo incontestável de conferir reconhecimento a outra tendência, tal como de lhe conceder grande visibilidade. Nesse sentido, alteraram o regulamento através de decreto-lei 9.378, feito às escondidas por Osvaldo Teixeira, diretor do Museu Nacional de Belas Artes (MNBA), com o intuito de legitimar suas pretensões conservadoras. Todavia, o mesmo foi revogado e como resultado não houve o salão neste ano. Os defensores da tradição buscavam asfixiar os modernos, de modo que tais precisavam optar entre ceder aos princípios rigorosos da Academia ou criar estratégias para romper as barreiras impostas. De acordo com Angela Ancora da Luz "durante toda a década podemos perceber que os modernos eram vistos como um corpo estranho que deveria ser extirpado e jamais acolhido novamente"3. Osvaldo Teixeira reforça explicitamente tal vontade.

Renina Katz ingressa em 1945 no curso de Pintura da Escola Nacional de Belas Artes (ENBA), portanto, acreditamos que tenha acompanhado o ocorrido, uma vez que o mesmo prédio onde estudava também abrigava o MNBA, na época a instituição responsável por sediar o evento. Em seu currículo consta que a sua primeira participação no Salão Nacional de Belas Artes (SNBA) aconteceu em 1948, no entanto, a informação se trata de um equívoco. Uma vez que não houve uma revisão 
sobre os dados, o mesmo foi reproduzido erroneamente, desse modo, em nenhum impresso consta a relação correta das exposições que participou. A consulta de fontes primárias, como os catálogos e notícias da época, permitem-nos ter uma comprovação do que foi dito, e até mesmo descobrir o que foi ignorado ou esquecido. Por exemplo, a primeira participação ocorreu um ano antes, em 1947, data de reabertura do Salão. Até 1959 esteve presente ininterruptamente no certame, o que Ihe permitiu obter diversos prêmios. Assim sendo, podemos dividir a sua presença em três fases: 1) inserção e conquista (1947-1950), 2) concorrência e progresso (1951-1956), 3) afastamento e transição (1957-1959).

A primeira fase tem como recorte o momento quando era aluna da ENBA, engajada com ações de movimento estudantil, época em que também subia os morros para pintar. Trata-se do período de formação, de aprendizado sistemático na instituição, mas também dos cursos livres e ateliers. Embora o seu nome seja vinculado ao de seus mestres, Axl Leskoschek e Carlos Oswald, a imprensa não se refere a ela como uma discípula submissa, ao contrário, aprendeu com eles o métier da gravura, mas possuía um traço e poética que lhe era próprio. Antonio Bento comenta que o método pedagógico adotado por eles buscavam orientar a descoberta a fim de alcançar a singularidade.

Apesar de iniciante, a artista apresentava qualidades para um futuro vitorioso, motivo para despertar atenção do júri. Conquista os prêmios de uma edição para outra, sem uma interrupção, sendo tal progressão responsável por indicar uma imediata inserção. Obtém no primeiro quadriênio todas as medalhas, restando como objetivo os prêmios de viagem. Por esse motivo, a primeira fase, além de remeter a inserção também corresponde às conquistas, as quais a afirmaram como artista de relevância.

Em sua inserção no circuito artístico oficial, expõe na Seção de Desenho e Artes Gráficas um único trabalho, intitulado Mulher Tricotando. Na época foi entrevistada por Ney Machado, responsável por publicar na Revista da Semana um artigo sobre a gestão de Osvaldo Teixeira. O repórter escolheu um grupo de jovens participantes do Salão para colher depoimentos, onde se encontrava Renina Katz. A artista expressa sua opinião, descreve o "perpétuo-diretor" do MNBA como um homem autoritário e cabotino, de postura antiética por conferir a si mesmo os prêmios do salão e devido às tentativas de beneficiar unicamente os seus pares. ${ }^{4}$

No ano seguinte, em janeiro de 1948, recebe a primeira láurea, uma Menção com Louvor na 
Seção de Desenho do I Salão da Sociedade Brasileira de Belas Artes (SBBA). A associação autônoma, que prezava pela defesa dos direitos dos artistas plásticos, foi uma das primeiras a rejeitar o regulamento de 1946. A fim de evitar que o episódio se repetisse criou o seu próprio certame, contudo, ao manter a mesma estrutura consistiu em repetição do primeiro. Rubem Navarra o descreve como uma versão menor do salão oficial, que não era capaz de despertar nenhum interesse especial na sociedade, principalmente devido o pequeno intervalo entre a realização dos eventos. ${ }^{5} \mathrm{~A}$ intenção foi boa, mas o resultado não.

Em dezembro, Renina conquista uma Medalha de Bronze na Seção de Desenho e Artes Gráficas do SNBA. Meses depois, o periódico O Momento Feminino publica a Gravura (Fig. 01), o que nos permite ter acesso o trabalho estimado pelo júri. Durante três edições seguidas, esteve presente no certame tanto nessa seção como na Seção de Pintura, onde apresentava os trabalhos realizados em decorrência de sua formação. Nesse sentido, a participação em duas seções ampliava as chances de conquistar os prêmios. Nesse ano foi a única vez que conseguiu expor 03 trabalhos em ambas, número máximo de inscrições permitidas no regulamento. ${ }^{6}$ Através dos títulos se torna possível observar que as temáticas predominantes eram a figura feminina e a natureza, as quais foram mantidas até a metade da década de 1950.

No ano seguinte, 1949, obtém Medalha de Prata. Silvia de Leon Chalreo publica na coluna de Artes Plásticas da Gazeta de Notícias um artigo sob o título A Mulher no Salão Nacional de 1949. Após listar os nomes de destaque no certame, sem fazer separação entre acadêmicas e modernas, aprecia o trabalho de Renina Katz, primeiro como gravadora, depois como pintora. Em relação às gravuras, indica que "suas 'águas-fortes' revelam uma artista que sabe utilizar a sua emoção e dar força às suas manifestações plásticas, jogando o branco e o prêto em seus mais belos contrastes." No Jornal do Brasil foi publicado um nota sobre os alunos do LAO, discípulos de Carlos Oswald, os quais se destacaram por receberem prêmios no Salão. ${ }^{8}$ Em relação a pintura intitulada Figura, única exposta neste ano, Silvia comenta que foi digna de destaque, sendo premiada por ser "um retrato que já é uma promessa com as suas côres e feitura plástica”. Por fim, também incentiva as leitoras a adquirirem o hábito de frequentar os salões.

Ainda referente ao LIV SNBA, Flávio de Aquino tece um breve comentário no Diário de Notícias

\footnotetext{
5 NAVARRA, Rubem. Novo Salão... Diário de Notícias, Rio de Janeiro, 01 fev. 1948. Movimento Artístico, p.3.

6 Decreto-Lei n ${ }^{\circ}$ 9.378, de 18 de Junho de 1946. Capítulo III - Da inscrição e da admissão. Art ${ }^{\circ} 72^{\circ}$.

7 CHALREO, Silvia de Leon. A mulher no Salão de 1949. Gazeta de Notícias, Rio de Janeiro, 18 set. 1949. Mulher, Artes Plásticas, p.3.

8 Poty Lazzarotto conquistou o Prêmio de Viagem ao País, Renina Katz e Lizete Almeida a Medalha de Prata, Cláudio Corrêa e Castro a Medalha de Bronze. Ver Liceu de Artes e Ofícios. Jornal do Brasil, Rio de Janeiro, 29 set. 1949. Educação e Ensino, p.10.
} 
sobre a Pintura no Salão, considerando-a lastimável em relação às edições anteriores. Sendo assim, dedica-se a escrever sobre os artistas menos conhecidos, os poucos que apresentam um bom trabaIho. Refere-se a Renina Katz como uma promessa, uma jovem com qualidades capazes de garantir um futuro vitorioso. ${ }^{9}$ No ano seguinte, esse mesmo crítico publica um texto referente O Salão de 50, com parágrafo dedicado especialmente para os artistas que configuraram a Seção de Desenho de Artes Gráficas, considerando-os "a única força real desta mostra”"10. Cita primeiro o nome dos artistas que se distinguem pelas láureas já obtidas no certame, para depois se referir aos mais jovens. Antes de uma questão de idade, o recorte se centra em desenhistas e gravadores com carreira inferior a 5 anos, os quais conquistaram notoriedade em um curto período. Eram em sua maioria discípulos de Carlos Oswald, sendo assim, parte do mérito também cabia ao mestre. Os jovens conferiram um novo sentido para essa que até pouco tempo era praticada por poucos ou como hobby.

Santa Rosa concorda com Flávio de Aquino, considerando Desenhos e Artes Gráficas como a melhor seção do LV Salão"11. De acordo com ele, Renina Katz estava bem representada, nessa edição onde expôs o linóleo Campo e a água-forte Velório. Aliás, no ano em questão ele foi júri da Seção de Pintura, onde a artista apresentou Atelier, a sua última participação como pintora no certame. Quirino Campofiorito, por sua vez, declara que "sua sensibilidade artística é notória, pintou timidamente "Atelier" (n 482). Suas águas-fortes tem maior pujança de expressão plástica."12. Não por acaso foram tais gravuras que lhe garantiram a Menção de Honra. Em relação à pintura, até o momento não foi possível encontrá-la, nem ao menos um registro fotográfico, restando apenas os comentários da imprensa.

Observamos como trilhou na primeira fase um percurso vitorioso, sem apresentar dificuldades de inserção, considerado igualmente um período de conquistas, pois contribuiu para alcançar rapidamente a afirmação no circuito artístico. A segunda fase, como veremos a seguir, representa uma série de mudanças. Além de um abandono da pintura, dedica-se cada vez mais a xilogravura, tal como substituí a temática genérica de antes por recortes mais específicos.

Em 1951 adquire o Prêmio de Viagem no País com a litografia Vigília (Fig. 2), enquanto Zélia Nunes, formada pelo curso de Escultura da ENBA, recebe o Prêmio de Viagem ao Estrangeiro. De acordo com Campofiorito, pela primeira vez duas mulheres foram detentoras do prêmio, uma

\footnotetext{
9 AQUINO, Flávio. O LVI Salão Nacional (I). Diário de Notícias, Rio de Janeiro, 28 ago. 1949. Momento Artístico, p.3.

10 AQUINO, Flávio de. O Salão de 50. Diário de Notícias, Rio de Janeiro, 19 nov. 1950. Movimento Artístico, p.3.

11 ROSA, Santa. As principais premiações do Salão na Divisão Moderna. A Manhã, Rio de Janeiro, 19 nov. 1950 . Letras e Artes, Artes Plásticas. p.9.

12 CAMPOFIORITO, Quirino. Figurativista no "Salão" - I. O Jornal, Rio de Janeiro, 04 nov. 1950. Artes e Espectáculos, Artes Plásticas, p. 11.
} 
[Figura 01]

Renina Katz. Gravura.

1948.

Gravura em metal. $20 \times 17$ $\mathrm{cm}$. Medalha de Bronze.
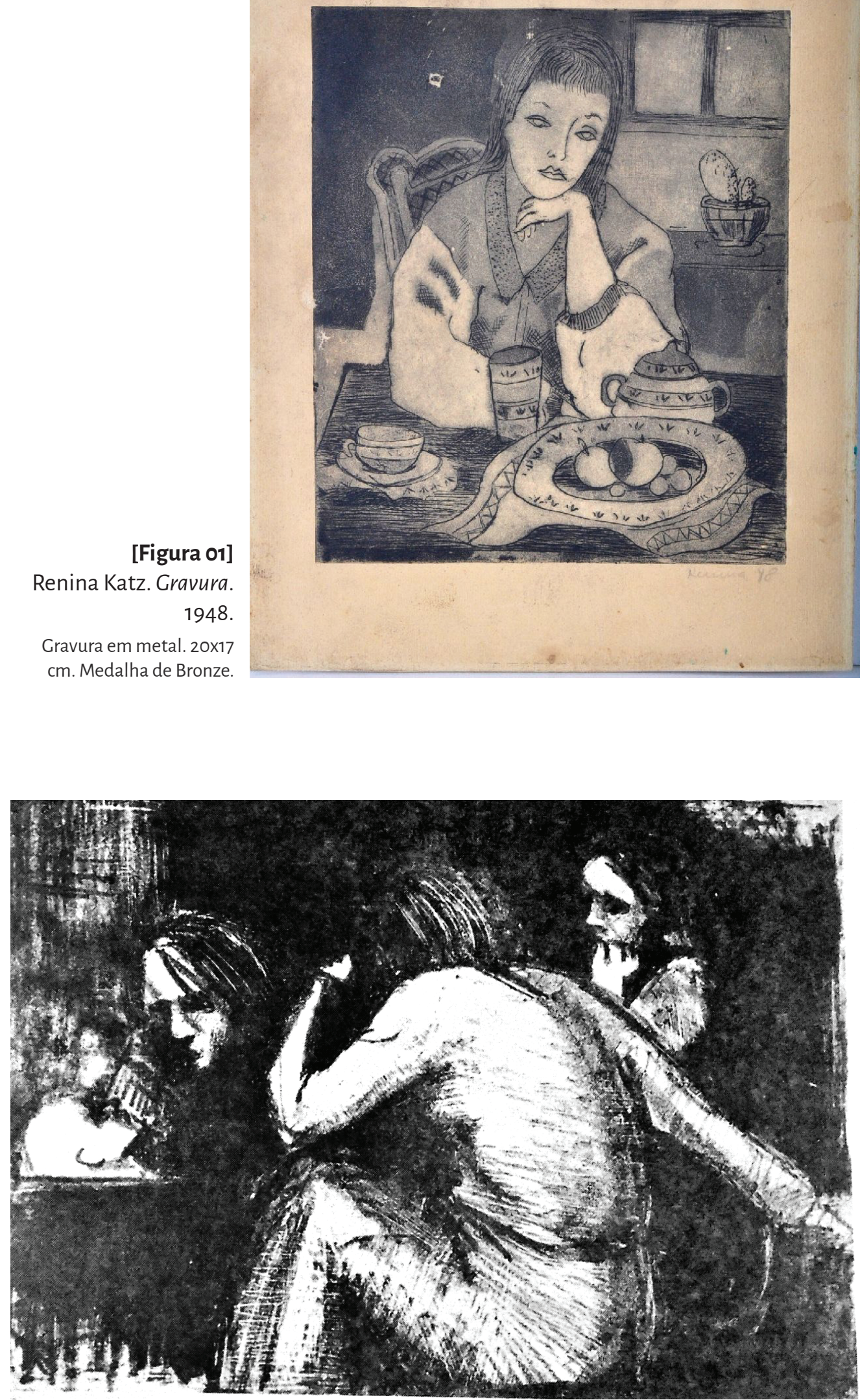

[Figura 02] Renina Katz. Vigília. 1951.

Litografia. 24×32 cm. Prêmio de Viagem ao País. 
conquista que merece destaque por contribuir com o estudo de gênero na história da arte. ${ }^{13}$ No catálogo constam dois trabalho de Renina Katz, uma Água-forte e uma Xilografia, em vista disso, nos questionamos se o crítico teria se equivocado. N'O Jornal aparece a gravura Barcos (Fig. 3) e na revista Fundamentos a litografia Figura (Fig. 4), ou seja, nenhuma delas condizem com o título e técnica anunciada como premiada. O primeiro consiste em uma gravura em metal, provavelmente a águaforte citada no catálogo, todavia, não corresponde a obra citada. As publicações nos periódicos nos provocam dúvida, desse modo, acreditamos se tratar de uma falha, que só foi possível ser sanada com a publicação do livro editado pela FUNARTE. ${ }^{14}$ Ao consultá-lo, percebermos que o erro se encontrava no catálogo, uma confusão entre as palavras xilografia e litografia.

De acordo com Campofiorito, a jornada com duração de 6 meses era uma oportunidade única, dado que pouquíssimos artistas conseguiam viajar sem ter um auxílio financeiro. ${ }^{15} \mathrm{O}$ crítico descreve que Renina:

(...) terá agora oportunidade de passar sua observação de artista, através de cenários novos, e plasmar em suas obras a vida do povo brasileiro, surpreendê-la nos recantos mais diversos dessa imensa nação, ora marcada ainda pelas sugestões de velhas tradições, ora mergulhada naquela pobreza que decorre do abandono dos responsáveis pela integridade moral e material das populações afastadas dos raros centros privilegiados. (...) A artista é uma criatura dotada para os sentimentos mais profundos e estreitamente ligados a existência humana. ${ }^{16}$

Viajou para diversos estados, como Bahia e Minas Gerais, de onde retornou com pastas repletas de estudos, os quais serviram para a produção de suas gravuras. A expectativa sobre o seu trabalho aumentou significamente, assim como a pressão para conquistar o último prêmio do salão.

Em 19 de dezembro de 1951, através do decreto 1.512, a arte moderna conquista o seu próprio Salão. Mantém-se as seções, mudam-se os prêmios. Não há mais medalhas ou menções, esses são substituídos por prêmios em dinheiro e certificado de isenção do júri. A Medalha de Prata do SNBA equivale a isenção do júri no novo certame, uma oportunidade de ser aprovado de imediato. No ano seguinte ocorre a primeira edição do Salão Nacional de Arte Moderna (SNAM), onde Renina Katz expõe o desdobramento de sua viagem. Mário Pedrosa se refere ao trabalho como lamentável, um caso escabroso, pois não apresentava nenhuma evolução. De acordo com o crítico, tais gravuras

\footnotetext{
13 CAMPOFIORITO, Quirino. Duas artistas laureadas no "Salão". O Jornal, Rio de Janeiro, o8 nov. 1951. Artes e Espectáculos, Artes Plásticas, p.7.

14 Arte Moderna no Salão Nacional 1940-1982. Rio de Janeiro: MEC/Secretaria de Cultura/ FUNARTE. 1983.

15 CAMPOFIORITO, Quirino. Os laureados na divisão moderna. O Jornal, Rio de Janeiro, o7 nov. 1951. p.8

16 Ibidem
} 


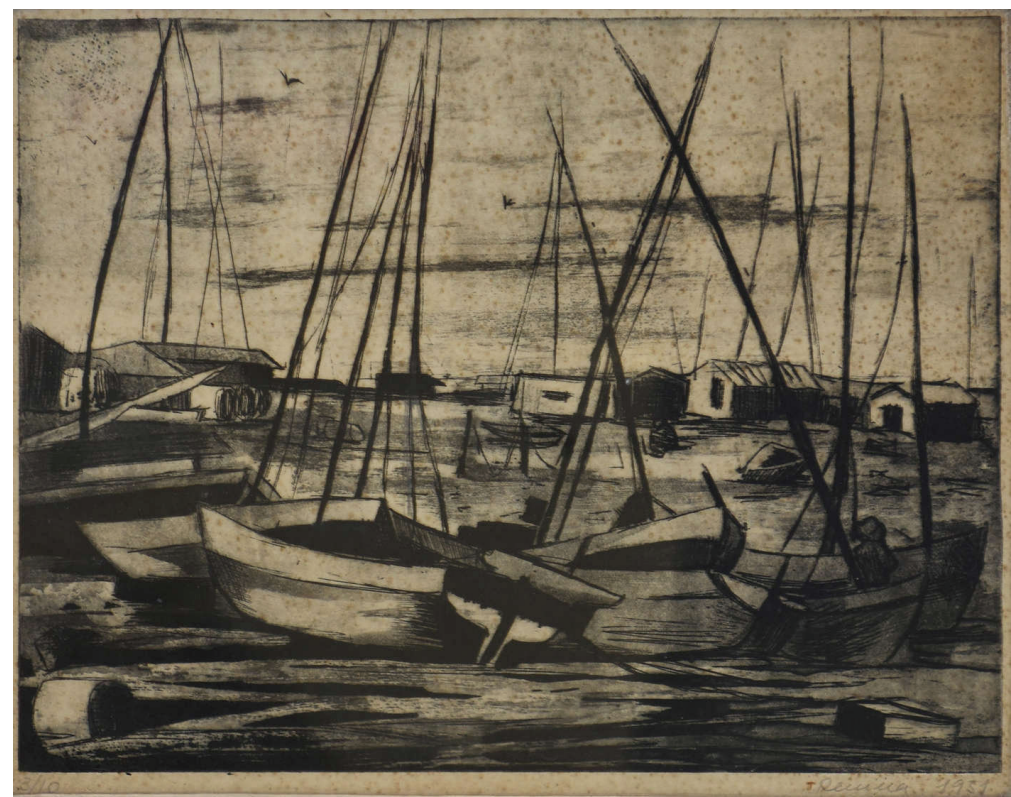

[Figura 03] Renina Katz. Barcos. 1951.

Gravura em metal

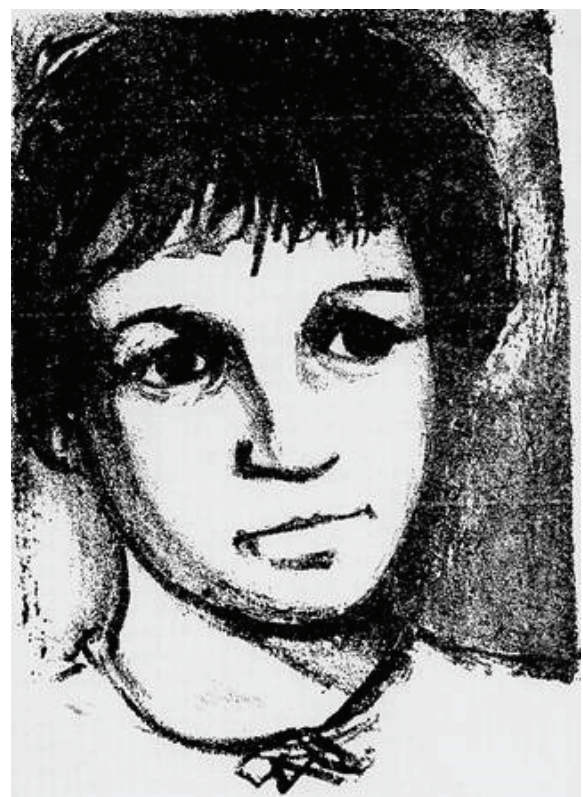

[Figura 04] Renina Katz. Figura. 1951. $23^{\circ}$ Edição da Revista Fundamentos, p.9.

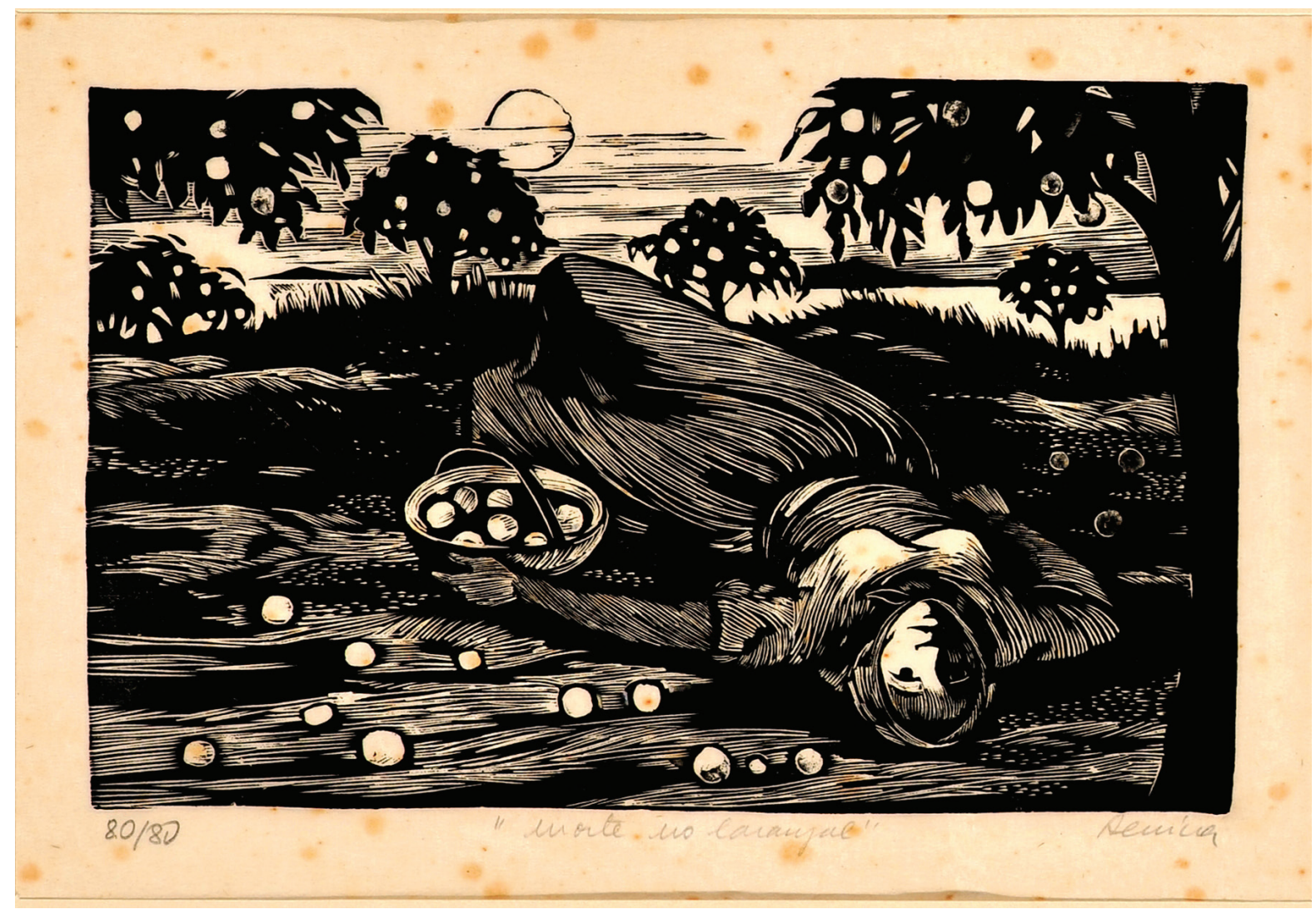

[Figura 05] Renina Katz. Camponesa Morta. 1955.

Xilogravura. $14 \times 22 \mathrm{~cm}$. Ilustração para o romance Subterrâneos da Liberdade de Jorge Amado. Capa da $37^{\circ}$ Edição da Revista Fundamentos. 
pareciam com tudo que fazia os outros realistas sociais, uma lamúria inexpressiva das causas humanas. E se na década de 1930 foi o responsável pelo texto emblemático sobre Käthe Kollwitz" artista-referência para os jovens gravadores, nesse momento se posicionaria contra o realismo social por entendê-lo como uma simples estetização da miséria humana.

Independente do descontentamento, a tendência crescia expressivamente, como declara Mário Barata em O atual surto realista. Em seu texto, refere-se a tendência como uma "vigorosa tentativa de expressão de um conteúdo humano através de uma forma plástica sólida e estruturada". Anuncia ao leitor a retomada da preocupação social na arte brasileira, dedicando-se especialmente à Renina Katz, gravadora que "realiza uma gráfica com mensagem humana e social. Essa sua iniciativa é a maior prova de sua liberdade artística e criadora". ${ }^{18}$ Barata será o responsável em 1954 por uma série de artigos sobre o III SNAM, que ficou conhecido popularmente como Salão Preto e Branco. Os artistas plásticos de todo o Brasil protestaram contra o governo, uma vez que o mesmo dificultava a importação de materiais. Os realistas compareceram em grande número, principalmente os gravadores, uma vez que naturalmente atendiam a proposta da exposição com seus trabalhos em preto-e-branco.

Há um quadriênio desde o último prêmio conquistado, participa no Salão em 1955 com três xilogravuras, ilustrações para o romance Subterrâneos da Liberdade de Jorge Amado. No mesmo mês da exposição, Camponesa Morta (Fig. 5) estampa a capa da antepenúltima edição da Fundamentos. Essa revista divulgava os trabalhos da artista, desempenhando função semelhante ao Momento Feminino no período anterior. Nessa segunda fase, criou-se inicialmente uma grande expectativa em relação aos trabalhos, mas devido o próprio funcionamento do salão, os críticos se limitarem a tímidos comentários, retomando atenção em 1956. No V SNAM alimentaram novamente a esperança, puderam manifestar suas apostas para o possível vencedor do Prêmio de Viagem ao Estrangeiro da Seção de Desenho e Artes Gráficas. A desvantagem era explícita, pois contemplavam um artista da Seção de Pintura e um outro das demais seções, condição que implicava um revezamento, uma vez que o regulamento proibia que a mesma seção recebesse o prêmio por mais de dois anos consecutivos. ${ }^{19}$ Em cada edição um pintor era premiado, enquanto o gravador precisava aguardar a sua vez. Entre os concorrentes estavam Aldemir Martins, Anísio Medeiros, Darel Valença Lins e

\footnotetext{
17 PEDROSA, Mário. As tendências sociais da arte e Kaethe Kollwitz. In: __. Arte necessidade vital. Rio de Janeiro: CEB, 1949. p.7-34

18 BARATA, Mario. Atual surto realista. Diário de Notícias, Rio de Janeiro, 23 ago. 1953. Suplemento Literário. Artes Plásticas, p.5.

19 Lei $n^{\circ} 1.512$, de 19 de dezembro de 1951, Art 13. § $3^{\circ}$.
} 
Renina $\mathrm{Katz}^{20}$. O primeiro obteve prêmio de 10 mil cruzeiros e nesse mesmo ano o Prêmio de Melhor Desenhista Internacional na Bienal de Veneza, onde Renina Katz também expôs. O segundo foi o grande vencedor do Salão, enquanto o terceiro venceu esse mesmo prêmio no ano seguinte, uma conquista louvável. Um ano antes, em 1955, Quirino Campofiorito já havia comentado que Anísio era um forte candidato ao prêmio. ${ }^{21}$ Em vista disso, percebemos que por mais que ela tenha progredido, existia uma concorrência acirrada. Na Bienal de Veneza, apresentou somente gravuras da série Camponeses em Terra: os Retirantes. Até essa edição exibe anualmente gravuras sobre a temática campesinato a fim de promover uma denuncia sobre as condições do trabalho rural. Portanto, restanos dúvida se algum dos trabalhos sem título pertencem a temática Favela, sendo na atualidade a série mais conhecida da artista, entretanto, jamais mencionada quando se trata dos salões.

Por fim, a última fase, a mais breve de todas. Trata-se de uma mudança significativa em sua produção, do abandona o preto e branco da gravura para se dedicar ao colorismo da pintura, aproximando-se de uma sensibilidade oriental. Nos dois últimos anos da década de 1950 passa a expor somente desenhos. Novamente recebe atenção de Mário Pedrosa, todavia, dessa vez ele a compara com Yozo Hamaguchi, pois se encontra "numa procura gráfico-pictórica hesitante entre os longes paisagísticos de perspectiva aérea e a matização de valores através da finura linear à japonesa". ${ }^{22} \mathrm{~A}$ imprensa nota a hesitação, que em parte corresponde a uma mudança radical em relação a proposta anterior, no entanto, independente disso aprovam o que consideram ser uma liberdade pictórica, sem as amarras temáticas e formais do realismo social. A partir de então, o seu novo interesse será a questão a composição cromática.

Afinal, o que a motivou participar do salão após 1956? Uma esperança de conquistar o prêmio? Uma busca por se manter presente em uma mostra nacional de grande relevância? A facilidade de expor devido a isenção do júri? A imprensa estava interessada em promover discursos sobre os novos nomes e tendências, a atenção se voltava cada vez mais para a abstração informal e o neoconcretismo. Ainda há muitas perguntas sem respostas, todavia, o presente texto se apresenta tanto como um panorama da participação de Renina Katz nos salões, quanto um estudo do discurso crítico frente aos trabalhos da artista, o que contribui para entender como se deu a sua inserção e manutenção no circuito artístico oficial.

20 CAMPOS, Fernando Coni. Ano Artístico. Almanaque Eu Sei Tudo, No Brasil, 1957. p.274.

21 CAMPOFIORITO, Quirino. Salão de Arte Moderna. O Jornal, Rio de Janeiro, 28 ago. 1955. p.2

22 PEDROSA, Mário. Salão Moderno - III. Jornal do Brasil, Rio de Janeiro, 25 nov. 1959. Primeiro Caderno, Artes Visuais, p.6. 
Referências bibliográficas

Arte Moderna no Salão Nacional 1940-1982. Rio de Janeiro: MEC/Secretaria de Cultura/ FUNARTE. 1983.

KATZ, Renina. Renina Katz - São Paulo: Editora da Universidade de São Paulo,1997. - (Artistas da USP 6)

LEITE, José Roberto Teixeira. A gravura Brasileira Contemporânea. Rio de Janeiro: Expressão e Cultura, 1966.

LUZ, Angela Ancora. Uma breve história dos salões de arte: da Europa ao Brasil. Rio de Janeiro: Ed. Caligrama, 2005. 